\title{
Effectiveness of Learning Management System for Teaching English Language at
}

\author{
Higher Education Level \\ * Dr. Afsheen Salahuddin \\ ** Dr. Fouzia Ajmal, Assistant Professor (Corresponding Author) \\ *** Dr. Saira, Lecturer
}

\begin{abstract}
The present research study was conducted in one of the private sector universities of Lahore city in Pakistan. This study has utilized a quantitative paradigm that included a single group pre-test posttest experimental design. The problem identified was a less developed English language grammar skill in the students and also how to teach English language successfully to the large classes i.e. consisting of 50 to 60 students. The main purpose was to develop some plans to facilitate the large classes. A single group quasi-experiment was conducted for four months (one semester) to find out whether the implementation of the Learning Management System (LMS) for the teaching of the English language is successful or not. The rationale of the study was to provide detailed lesson plans and analysis of how the teaching is done through the LMS in large English language classes like having 50 to 65 students per class. The results showed that LMS or the Learning Management System proved to be successful for teaching English to large classes as it saved time for the teachers and students both along with providing ample guidance and support. The present study is significant as it provides a guideline for other institutes on how they can also utilize this software effectively for teaching the English language.
\end{abstract}

Keywords: Learning Management System, Grammar Skills, Large Classes

\section{Introduction}

With the advent of science and technology, the competition in every field in the present world has become more and more challenging. People all over the world know that to compete with the modern world, they need to be well versed in the English language as this is the most spoken language of the world and secondly people also need to be aware of the modern education strategies like ICT or information communication technologies, being utilized in today's world. In today's world, we need to learn things quickly as IT is emerging and progressing at a fast pace (Woolf, 2010).

Online education programs have become popular with time as they enable the instructors to teach with a lesser workload and the hassle of marking and checking is gone. Moreover, it saves time for both the students and the instructor. This research is a small-scale study that was done to find out the effectiveness of LMS for teaching the English language.

Nowadays we all know that being good in English language skill has become very important and the people who have command over this language get good jobs and a great career. Online learning can also play an effective role in teaching the English language if implemented properly. According to Venkatrama and Zaheer (1990), IT-based applications have gained so much popularity in a lot of fields and have developed a strong competition among different companies or firms or fields. The same is the case with education where we can see a lot of IT based applications and programs being developed for teaching.

The main issue which was generally observed by the instructors and which was also pointed out by the students themselves was the lack of awareness about the Basic English grammar. Although the students had studied English courses throughout their school and college still they stated that they need a lot of practice in the English language. In our context, the university authorities need to develop proper planning for the English language course which is a compulsory course for any

* Faculty at Beaconhouse National University, Lahore-Pakistan Email: afsheensalahuddin50@ gmail.com

** Department of Education, International Islamic University Islamabad, Pakistan

Email: fouzia.ajmal@iiu.edu.pk

*** Department of Education, University of Gujrat, Pakistan Email: saira.usman@uog.edu.pk 
bachelor's degree. The university students are coming from various colleges and schools and therefore there is a lot of discrepancy among them.

In our context, there are public and private sector institutes that have their educational policies. The private sector institutes are English medium, therefore, the students who study there have a better grip on the English language as compared to the public sector institutes where even now the grammar-translation method is being followed for teaching the English language. By keeping this fact in mind, the institute planned to conduct a pre-test to identify their students' English language shortcomings and then plan the lessons accordingly. Many universities start teaching the English language at the university level without taking this point in mind, therefore, students show no improvement because they just rote learn and pass the English language course. Another problem was how to manage large classrooms and teach them effectively their English language courses. These problems were resolved by utilizing the LMS as it facilitated the students and the instructors and a lot of time was saved.

This is a small scale experimental study. The main purpose of this research was to see how the English language can be taught effectively to large classes through online learning techniques.

The research was conducted on 55 students of the computer sciences department of a private sector university. The students were taught through the LMS or the learning management system for one semester.

\section{Objective of the Study}

The main objective of the study was to plan the English language classes on LMS to facilitate the large English language classes of the first semester and also to see whether these lessons can be utilized effectively for the future first-semester students or not.

\section{Literature Review}

For teaching any subject to the students, one important factor is the interaction, and especially for teaching the English language interaction plays a major role. Palloff and Pratt (1999) have stated that interaction among students and between students and teachers is crucial in the teaching and learning process. In the classes, where there is a large number of students interaction becomes very challenging for both among students and between students and teachers. In such types of classes, integrated lessons can be successful as the instructor is not able to interact with each student effectively. Due to these factors, online education has become popular and each year thousands of students are enrolled in online courses. Moreover, educational institutes are also utilizing the online education systems for the effective teaching of certain courses.

According to Allen and Seaman (2008), there is a rapid growth of online education with time proving their success and this growth is not reducing. They stated that many people who are working tend to enhance their profile through online education programs. There has also been a link between the online education enrolment and the unemployment rate. Unemployed people also tend to get enrolled in online education to upgrade their education instead of wasting their time.

In Pakistan, Allama Iqbal Open University is the sixth-largest university in the world. Thousands of students get enrolled in their online education and distance education programs every year. The newspaper "Daily Pakistan" has reported in its February 2019 issue, that Allama Iqbal Open University in Pakistan sets a record of highest online enrolments in the semester of autumn 2018. More than seven lac students got them registered during this semester. Therefore we can see an increasing trend in getting online education in Pakistan as well. Therefore, many online education systems have been developed by the educational institutes for their students.

Rovai (2003) states that there has been continuous effort to develop several theoretical models of higher education which were based on psychological grounds and online education is also one of these efforts which turned out to be quite successful.

The ICT or information communication technology is emerging to be utilized in the educational sector as well as in other fields like business, medical etc. The LMS has also become quite popular to be implemented for teaching in the educational sector. Mikre (2011) has elaborated that ICT nowadays is influencing every aspect of human life like at workplaces, education, and business places. The ICT has also brought a lot of changes in the workplaces and also in the education sector whether at the school level or the higher education level. The online integration of games with education has also created progress in students' learning especially at the school level (Minovic et al 2012). 
Altun (2007) further elaborates the point by stating that ICT programs have been successfully implemented internationally like in Turkey, Britain, America, and Japan. He further explains that there are four things to be kept in mind for the ICT implementation which are the following: Infrastructure, physical resources, curriculum, and policy development.

In the present study, these factors have been kept in mind as well for the development of the LMS program as the program caters to the needs of the students and has been designed following the English language curriculum. The classes have been constructed bigger in size for the computer sciences department and the curriculum is also designed to keep the number of students in mind like more online activities are utilized. The instructor is provided with the freedom to teach according to the students' requirements.

There are many barriers which hinder the successful implementation and usage of ICT especially in developing countries like Pakistan as explained by Buabeng-Andoh (2012) when he states that lack of IT skills of the instructors, teacher's lack of confidence in using the ICT technologies, lack of teachers' ICT training and limited access to the ICT. Moreover, sometimes the traditional teachers and policymakers do not want to use the latest educational pedagogies. Here in the present research, a teacher training workshop was conducted to train the teachers to effectively use the LMS. Moreover, the institute had quite a flexible approach towards the curriculum which was revised according to the needs of the students.

The institute where this research study took place developed an LMS program for their students by keeping in mind their needs and students like to study on LMS as their material is always saved and available there. Students also think that this is easier as compared to submitting hard copies and their mistakes and scores are also displayed right after their quizzes.

Heckhausen and Kuhl (1985) have emphasized that motivation is an important factor for the students to learn or stay enrolled in an online educational program. Carr (2000) has also elaborated the fact that students' completion of the course is important and for this purpose keeping their interest intact throughout the course is a challenging task. In the present research study, the online English course has also been planned by keeping in mind these factors. The online quizzes have been designed in such a way to keep the interest of the students intact. Some of the quizzes have been made by the researcher in the form of a story which made the students learn interestingly by keeping them engrossed in suspense. The online feedback also showed that most of the students liked the stories created by the researcher.

Moore and Kearsley (1996) have stated that students who take online classes learn to utilize a self-directed approach where they diagnose their shortcomings and then try to improve. In this research study, the self-directed learning factor was kept in mind. The material which was taught was kept available for the students so that they refer to it whenever they want and learn anytime which is convenient for them. In the present study, a quiz was developed as the pre-test which was based on the basic grammar like nouns types of nouns. adjectives, adverbs, verbs, conjunctions, prepositions, and verb forms. The scores in the pre-test helped the students to identify their mistakes.

The present research study is a small scale research study conducted to devise some method to facilitate teaching and learning in large English language classrooms having 50 to 65 students. In this study, the researcher is trying to find out how the large English language classes can be managed. The present study has utilized the quantitative data which has been gathered from a single group pretest post-test experimental design.

The experimental research design has been used in educational research for ages. This is one of the most popular research design. One thing as narrated by Gersten, Baker, and Lloyd (2000) is that if the subjects know that they are part of an experiment then the results may be affected. Therefore in the present research, the students were not informed by the researcher about any experimental research being conducted on them to get authentic results.

Huck and McLean (1975) have elaborated that the control group experimental design is quite popular as it provides a comparison group to compare the performance of the experimental group with it. According to Dimitrov and Rumrill ( 2003), the pre-test post-test experimental designs have always been popular for comparing the groups in the experimental studies.

The main purpose is to find out a way to facilitate learning in a large classroom and to find out what happens when LMS or the learning management system is utilized for teaching the English language in a large classroom therefore no comparison group was needed. Moreover, as the students' 
population was homogenous i.e. same age group, same educational background, and were studying in the same semester therefore the control group was not crucial to be added in the research. The study was not aimed to see how much students have improved through the lesson conducted on LMS therefore no control group was needed for the present study to compare the performance.

\section{Methodology and Paradigm}

This study has utilized a quantitative paradigm as it conducted a single group pre-test post-test design. The main purpose was to find out whether the implementation of LMS for the teaching of the English language is successful or not and for this purpose, the quantitative paradigm was suitable as getting the qualitative data from a large class was challenging, within a single semester. Therefore the data was collected quantitatively. The pre-test and post-test scores were compared to see the effectiveness of LMS for teaching English language courses.

\section{Population and sample}

The population of the study was the university students of Lahore aged between 17 to 19 years. A purposive sampling technique was utilized. The first-semester university students were purposely chosen from the Computer Science department of the private sector institute for the present research. Tongco (2007) has elaborated the purposive sampling technique as follows, purposive sampling technique is a type of non-probability technique which is utilized when one wants to study or intensively study a certain cultural group. This technique can be utilized with both qualitative and quantitative research techniques. Here in the present research, a group of 55 first semester students were selected to see how they can be facilitated in learning the English language in a large classroom setting. A single group pre-test post-test design was also utilized on the purposely selected sample of first semester, 55 students.

\section{Procedures}

For learning the English language in our context it is important to learn about the basic rules of the English language as this is our second language. It was identified through the scores of the pre-test that most of the students do not have a clear understanding of the Basic English grammar rules. This study was primarily done to find out how the students and teachers can be facilitated to learn and teach the English language effectively through LMS.

This study was a single group pre-test post-test quasi-experimental study where a single group of 55 students was taught through the LMS and their pre-test and post-test scores were compared to see whether the LMS can be utilized in the future for teaching English language courses to large classes or not. The research was conducted on 55 first-semester students of the computer sciences department of the private sector university for one semester i.e. four months. First of all the pre-test was conducted which was based on the Basic English grammar and parts of speech. like, nouns, types of nouns, adjectives, verbs, adverbs, verb forms, prepositions, and conjunctions.

The scores showed that the majority of the students were not aware of the Basic English grammar or have forgotten whatever they have learned in their elementary classes about the Basic English grammar. Therefore the lessons were planned accordingly. In every one and a half hour duration class, there was an explanation of some grammar rule or part of speech and in the next class, there was a quiz based on the previous lecture. The progress of the students was monitored daily through the scores and the bar graphs on daily basis. In the end, the post-test which was the same as the pre-test was conducted. When the scores of the pre-test and post-test were compared, it was found that the students have shown progress. Therefore the same strategy was followed for the upcoming first-semester students.

The very first lesson was conducted on Nouns and their types. In the second lesson, a quiz was taken based on the previous lecture. The same pattern was followed for the whole semester. First, there was an explanatory lecture on some grammar rules then there was a quiz. There were a total of 16 classes each semester for four months. The pre and post-tests were conducted in two classes and the rest of the fourteen classes were divided between the explanatory lectures and the quizzes that is, there were seven explanatory lectures and seven quizzes. The seven explanatory lectures were conducted on Nouns and its types and adjectives (one explanatory lecture and one quiz ), Verbs and adverbs (one explanatory lecture and one quiz), verb forms (three lectures and three quizzes ) Conjunctions (one explanatory lecture and one quiz), Prepositions, (one explanatory lecture and one quiz). There was one lecture each for every topic while there were three lectures and three quizzes for the verb forms as this area needed more attention. Students themselves stated that they needed more 
practice in verb forms and it was something positive as the students were aware of their short coming $\mathrm{s}$ and were interested in learning and improving.

In every explanatory lesson, students were explained the grammar rules or the parts of the speech. There was always a class discussion at the end of every explanatory lesson. In the next class, the quiz was conducted based on the previous lecture. The teacher prepared the quiz on LMS. Each quiz was of ten marks each. There was a certain time limit set like twenty minutes for each quiz. The quiz was available to be conducted during the class timings only. For example, if the class starts at midnight and ends at 1:30 am then the quiz will no longer be available to be attempted $b$ the students. This made the students come to the class on time as well along with learning.

The scores of the students were displayed on each of the students' LMS portals and they were shown on the teacher's portal as well. The teacher could also see how many students were absent. The bar graphs were shown on the teacher's portal only to assess the improvement level of the students. Figure 1 demonstrates the bar graph representation of one of the quizzes generated by the LMS.

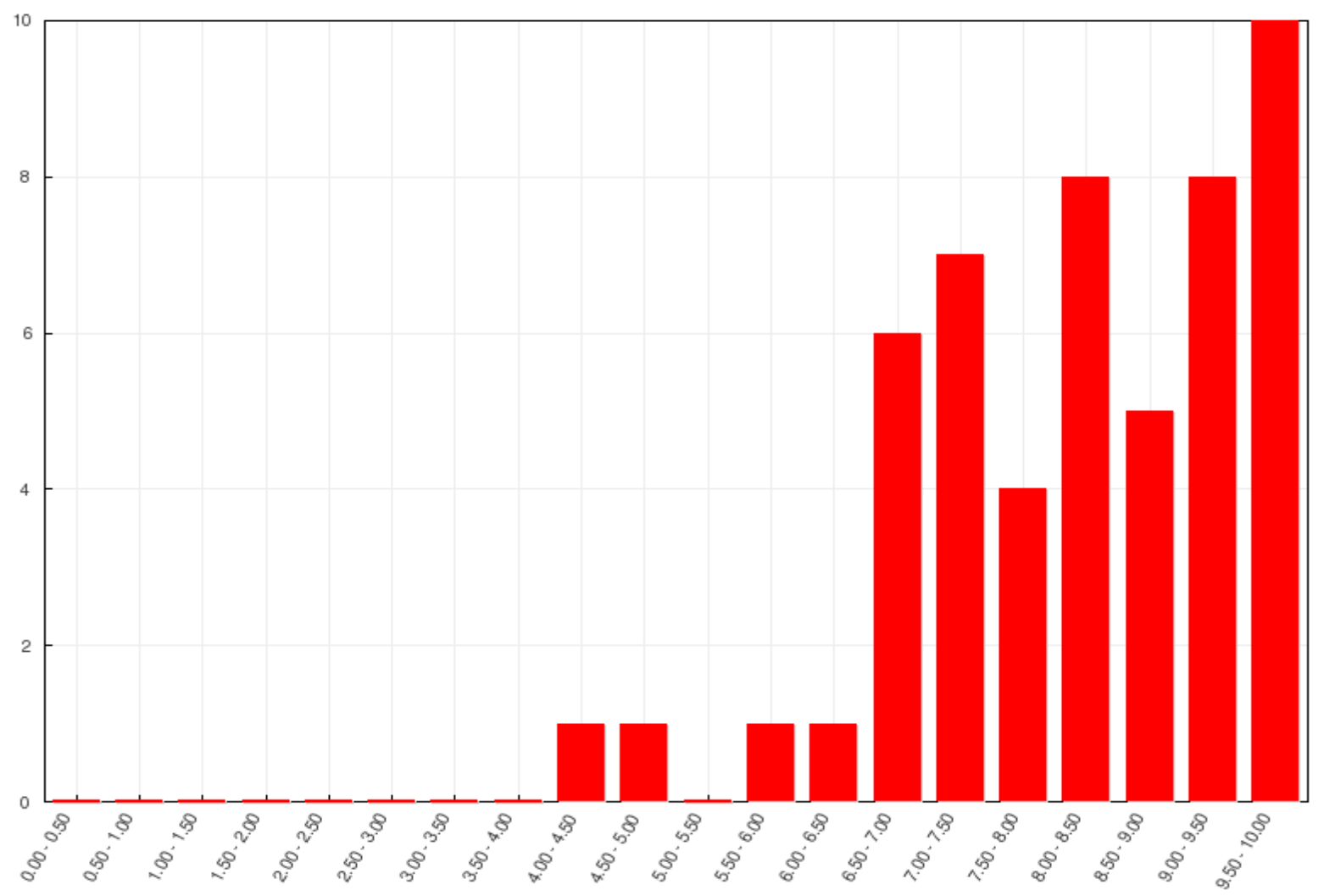

Figure 1 Scores of one of the quizzes

Figure 1 provides the bar graph of one of the quizzes generated by LMS. The bar graph is available for the teachers while each student gets his/her score sheet. From this bar graph, the teacher can easily see the scores of the students and this also indicates whether any improvement has been shown by the students or not. Here the lowest score is 4 and the highest is 10 out of the total score of 10. This indicates that some students need individual attention. A lot of time is saved as the result is displayed immediately after each quiz and the teachers can easily identify the weak students. Therefore both teachers and students have been facilitated through the lessons planned on LMS

\section{Data Presentation and Analysis}

Table 1-Pre-test and the post-test scores of the students

\begin{tabular}{lll}
\hline & Pre-test scores & Post-test scores \\
\cline { 2 - 3 } 1 & 7.4 & 8.4 \\
2 & 9.32 & 10 \\
3 & 5.45 & 7.38 \\
4 & 7.8 & 9.09 \\
5 & 7.86 & 8.41 \\
6 & 6.9 & 8.86 \\
7 & 9.29 & 7.95 \\
\hline
\end{tabular}




\begin{tabular}{|c|c|c|}
\hline 8 & 8.1 & 9.09 \\
\hline 9 & 9.09 & 9.52 \\
\hline 10 & 4.76 & 8.41 \\
\hline 11 & 7.14 & 7.5 \\
\hline 12 & 6.43 & 7.5 \\
\hline 13 & 7.20 & 9.09 \\
\hline 14 & 8.81 & 9.09 \\
\hline 15 & 8.41 & 9.52 \\
\hline 16 & 7.05 & 8.33 \\
\hline 17 & 9.76 & 9.09 \\
\hline 18 & 8.64 & 9.05 \\
\hline 19 & 8.41 & 9.76 \\
\hline 20 & 7.14 & 9.09 \\
\hline 21 & 7.27 & 7.38 \\
\hline 22 & 9.29 & 9.32 \\
\hline 23 & 8.41 & 8.81 \\
\hline 24 & 8.33 & 8.86 \\
\hline 25 & 7.73 & 7.86 \\
\hline 26 & 6.36 & 8.1 \\
\hline 27 & 7.86 & 8.64 \\
\hline 28 & 8.1 & 8.41 \\
\hline 29 & 8.41 & 9.52 \\
\hline 30 & 8.57 & 9.09 \\
\hline 31 & 4.05 & 8.41 \\
\hline 32 & 8.81 & 8.86 \\
\hline 33 & 8.41 & 9.05 \\
\hline 34 & 8.1 & 9.09 \\
\hline 35 & 9.09 & 9.76 \\
\hline 36 & 6.67 & 7.5 \\
\hline 37 & 5.71 & 8.64 \\
\hline 38 & 8.64 & 9.76 \\
\hline 39 & 7.73 & 9.09 \\
\hline 40 & 6.9 & 7.73 \\
\hline 41 & 8.86 & 9.05 \\
\hline 42 & 6.67 & 9.09 \\
\hline 43 & 7.38 & 8.64 \\
\hline 44 & 8.1 & 9.09 \\
\hline 45 & 9.09 & 9.09 \\
\hline 46 & 7.14 & 9.09 \\
\hline 47 & 6.59 & 6.67 \\
\hline 48 & 6.9 & 7.73 \\
\hline 49 & 7.14 & 8.64 \\
\hline 50 & 8.1 & 9.09 \\
\hline 51 & 5.05 & 8.01 \\
\hline 52 & 7.27 & 7.74 \\
\hline 53 & 6.8 & 9.09 \\
\hline 54 & 7.4 & 9.09 \\
\hline 55 & 5.71 & 9.76 \\
\hline
\end{tabular}

As shown in table: 1, students have shown improvement in the post-test scores. The LMS calculates the marks according to the time taken by each student during the quiz hence this also shows how speedily the students have done their quiz which indicates that how strong is the grip of the students. Students themselves stated that they feel at ease because their material is available on the LMS and is accessible anytime. Moreover, they were also happy about getting feedback on their attempted quizzes quickly.

The scores ranged from 5.05 to 9.76 in the pre-test while the range of scores in the post-test increased to 7.3 to 10 which shows the progress of the students.

Berggren (2005) states that although LMS was developed for being utilized in a variety of departments but its popularity and usage in the education department is more successful. This statement is in compliance with the data collected from the present research. 
The data collected is in compliance with the previous studies done on the same issue as discussed below:

Conijn et al (2016) states that students' online behavior can be easily observed via LMS as it provides a detailed account of their performance through bar graphs etc.

Ghilay (2019) researched 45 lecturers about the usage of LMS. He found out that the instructors who use Moodle or LMS more than those who used less had a more efficient teaching and learning environment as the course-related activities and material was always available for the students. He has further pointed out that students' success is also directly proportional to the degree of effort a teacher puts in the usage of LMS. (Ghilay, 2017)

Govindasamy (2001) has also elaborated that many institutes and corporate training institutes are preferably utilizing the E-learning techniques for their students due to the emerging trends all over the world for online education and embracing progress. Liaw et al (2017) further strengthens the same point by stating that e-learning is the new rapidly increasing trend in today's world with positive results. Kasuma(2018) researched 265 students in a Malaysian university. The results suggested that the students prefer to study via LMS and social media. Al-Ani (2013) researched the Qaboos University in Oman including 283 students and the results showed that LMS usage affects the motivation level in students.

Mtebe (2015) has stated that LMS has been implemented in the education institutions in subSaharan Africa as well with positive results although the limited resources sometimes are a hindrance to the installation of LMS. Ngeze (2016) stated that in Tanzania also the implementation of LMS is not without challenges in the educational institutes as it requires a lot of expenditure and investment even then their popularity has not diminished.

Eom, 2001 conducted research on university students to find out their satisfaction level for using LMS and found out that the students' responses ranged from "extreme likeness" to "extreme dislike" which showed that instructors need to utilize the LMS by keeping in mind students' preferences as well, as was done in the present study, only them the LMS will be successfully implemented. Shee \& Wang (2008) have also stated that students' satisfaction plays a crucial role in the successful implementation of LMS as shown by the results of their study done on college students.

A research study conducted in the Philippines on undergraduate Engineering students showed positive feedback from the teachers and students on using the LMS in the institute. Kurata et al (2017). The present study's results also showed the same findings as the above-discussed studies.

\section{Findings and Recommendations}

The following were the findings of the present research study along with some recommendations:

1. Students and teachers felt comfortable while using the LMS.

2. The teachers' workload was reduced thus making them available for students for more time.

3. The LMS implementations helped the weaker students get more time from their instructor.

4. Students 'learning material was always available on LMS and they could access it whenever they wanted.

5. Immediate feedback was provided after every quiz thus enabling students to identify their mistakes.

6. Teachers were able to monitor their students' progress more conveniently as the bar graphs and scores of the students were calculated and shown daily by the LMS.

7. One negative aspect which was found out was that sometimes students did not come to the class and attempted the quiz outside the classroom. This problem was resolved by asking teachers to count the number of students present and then check how many quizzes have been submitted.

8. Another issue which was faced by the students and the teachers was the disconnectivity of the internet or limited access to the internet which at times disturbed the class. This issue needs to be taken into consideration and a proper internet should be provided in the educational institutes where the online teaching course are being taught.

9. Another quite hectic thing was the formation of the online accounts. This was difficult as the students were using this program for the first time, so another instructor's help was utilized to enroll all the students into the LMS. 
10. The setting in the LMS was adjusted in such a way that the LMS quizzes access was only available within the vicinity of the university only while the other material, notes, and presentations were available anywhere for the convenience of the students.

11. The LMS proved to be quite easy to be handled by the teachers as they simply had to drag and drop the files there for their students but the creation of quizzes was not so easy as the teachers had to enter and save each question individually which took a lot of time so this aspect needs to be improved.

12. LMS turned out to be useful for larger classes as it can cater to the needs of thousands of students at one time. Thousands of students can attempt quizzes on the LMS and the result is generated immediately after.

13. LMS can be designed according to the needs of the students as was done in the present study and students could learn according to their desired pace.

14. Teachers easily organized their course on LMS according to the dates and a lot of time was saved.

15. Teachers found this hassle-free and time saving as a lot of time which was spent on marking quizzes was saved.

16. The students knew that the results shown were free of any bias as they were generated by the LMS.

17. It was observed that some of the students also tried to cheat in the quizzes because students who were sitting side by side could easily glance at the computer screen of the other student sitting next to them. Therefore it was proposed that two versions of each quiz should be prepared or if there is one version then students should be seated individually.

\section{Conclusion}

The teaching of the English language turned out to be successful through LMS as it reduced the workload of teachers. Moreover, students were provided the feedback quicker than the hard copies. This also made the students well aware of their mistakes and the immediate result displayed on the LMS also enabled the students and the teachers to track their performance daily. The teachers were able to give more time to the weaker students as the checking or marking time was reduced. Students also felt more relaxed as their material was always accessible on LMS.

This study also highlighted the fact that students need to be trained before utilizing the LMS and there should be a curriculum that has been devised keeping in mind the needs of the students. In many educational institutes where people who are not trained well enough they cannot get the desired results by using the LMS. Thus it is proposed that LMS or other programs of the same kind should be utilized for teaching English language courses but trained teachers should be available to effectively utilize this software.

\section{References}

Al-Ani, W. T. (2013). Blended Learning Approach Using Moodle and Student's Achievement at Sultan Qaboos University in Oman. Journal of Education and Learning, 2(3), 96-110.

Allen, E., \& Seaman, J. (2008). Staying the course: online education in the United States 2008. The Sloan Consortium. Babson Survey Research Group.

Altun, T. (2007). Information and communications technology (ICT) in initial teacher education: What can Turkey learn from a range of international perspectives?. Journal of Turkish Science Education, 4(2), 44.

Berggren, A., Burgos, D., Fontana, J., Hinkelman, D., Hung, V., Hursh, A., \& Tielemans, G. (2005). Practical and pedagogical issues for teacher adoption of IMS learning design standards in Moodle LMS. Journal of Interactive Media in Education, 2005(1).

Buabeng-Andoh, C. (2012). Factors influencing teachersâ adoption and integration of information and communication technology into teaching: A review of the literature. International Journal of Education and Development using ICT, 8(1).

Carr, S. (2000). As distance education comes of age, the challenge is keeping the students. Chronicle of higher education, 46(23).

Cole, R. A. (Ed.). (2000). Issues in Web-based pedagogy: A critical primer. Greenwood Publishing Group. 
Conijn, R., Snijders, C., Kleingeld, A., \& Matzat, U. (2016). Predicting student performance from LMS data: A comparison of 17 blended courses using Moodle LMS. IEEE Transactions on Learning Technologies, 10(1), 17-29.

Dimitrov, D. M., \& Rumrill Jr, P. D. (2003). Pretest-posttest designs and measurement of change. Work, 20(2), 159-165.

Eom, S. B. (2014). Understanding e-learners' satisfaction with learning management systems. Bulletin of the IEEE Technical Committee on Learning Technology, 16(2), 3.

Gersten, R., Baker, S., \& Lloyd, J. W. (2000). Designing high-quality research in special education: Group experimental design. The Journal of Special Education, 34(1), 2-18.

Ghilay, Yaron. "Effectiveness of learning management systems in higher education: Views of Lecturers with different levels of activity in LMSs." Journal of Online Higher Education vol $3.2(2019)$.

Ghilay, Y. (2017). Online learning in higher education. New York, NY: Nova Science Publishers.

Govindasamy, T. (2001). Successful implementation of e-learning: Pedagogical considerations. The internet and higher education, 4(3-4), 287-299.

Heckhausen, H., \& Kuhl, J. (1985). From wishes to action: The dead ends and short cuts on the long way to action.

Huck, S. W., \& McLean, R. A. (1975). Using a repeated-measures ANOVA to analyze the data from a pretest-posttest design: A potentially confusing task. Psychological Bulletin, 82(4), 511.

Kasuma, S. A. A., Saleh, M. S. M., Akhiar, A., \& Ismail, Y. M. B. (2018). Malaysian University Students' Preferences of Social Media and LMS in Academia. International Journal of Virtual and Personal Learning Environments (IJVPLE), 8(1), 51-67.

Kurata, Y. B., Bano, R. M. L. P., \& Marcelo, M. C. T. (2017, July). Effectiveness of learning management system application in the learnability of tertiary students in an undergraduate engineering program in the Philippines. In International Conference on Applied Human Factors and Ergonomics (pp. 142-151). Springer, Cham.

Liaw, S. S., Huang, H. M., \& Chen, G. D. (2007). Surveying instructor and learner attitudes toward elearning. Computers \& Education, 49(4), 1066-1080.

Mikre, F. (2011). The roles of information communication technologies in education: Review article with emphasis to the computer and internet. Ethiopian Journal of Education and Sciences, 6(2), 109-126.

Minovic, M., Milovanovic, M., Minovic, J., \& Starcevic, D. (2012). Integrating an educational game in Moodle LMS. International Journal of Distance Education Technologies (IJDET), 10(4), $17-25$.

Moore, M. G., \& Kearsley, G. G. (1996). Distance education: A system view. Wadsworth.

Mtebe, J. (2015). Learning management system success: Increasing learning management system usage in higher education in sub-Saharan Africa. International Journal of Education and Development using ICT, 11(2).

Ngeze, L. V. (2016). Learning management systems in higher learning institutions in Tanzania: Analysis of students' attitudes and challenges towards the use of UDOM LMS in teaching and learning at the University of Dodoma. Foundation of Computer Science.

Palloff, R. M., \& Pratt, K. (1999). Building learning communities in cyberspace. San Francisco, CA: Jossey-Bass.

Rovai, A. P. (2003). In search of higher persistence rates in distance education online programs. The Internet and Higher Education, 6(1), 1-16.

Shee, D. Y., \& Wang, Y. S. (2008). Multi-criteria evaluation of the web-based e-learning system: A methodology based on learner satisfaction and its applications. Computers \& Education, 50(3), 894-905.

Tongco, M. D. C. (2007). Purposive sampling as a tool for informant selection. Ethnobotany Research and applications, 5, 147-158.

Woolf, B. P. (2010). Building intelligent interactive tutors: Student-centered strategies for revolutionizing e-learning. Morgan Kaufmann.

Venkatraman, N., \& Zaheer, A. (1990). Electronic integration and strategic advantage: a quasiexperimental study in the insurance industry. Information Systems Research, 1(4), 377-393. 